19 Revue d'histoire du XIXe siècle

Société d'histoire de la révolution de 1848 et des

révolutions du XIXe siècle

$57 \mid 2018$

Libido sciendi

\title{
Julien PASTEUR, Les héritiers contrariés. Essai sur le spirituel républicain au $\mathrm{XIX}^{\mathrm{e}}$ siècle
}

\section{Christophe Voilliot}

\section{OpenEdition \\ Journals}

Édition électronique

URL : https://journals.openedition.org/rh19/6191

DOI : $10.4000 /$ rh19.6191

ISSN : $1777-5329$

Éditeur

La Société de 1848

Édition imprimée

Date de publication : 26 décembre 2018

Pagination : 208-209

ISSN : 1265-1354

Référence électronique

Christophe Voilliot, « Julien PASTEUR, Les héritiers contrariés. Essai sur le spirituel républicain au XIXe siècle ", Revue d'histoire du XIXe siècle [En ligne], 57 | 2018, mis en ligne le 26 décembre 2018 , consulté le 21 janvier 2022. URL : http://journals.openedition.org/rh19/6191 ; DOI : https://doi.org/ 10.4000/rh19.6191

Ce document a été généré automatiquement le 21 janvier 2022.

Tous droits réservés 


\title{
Julien PASTEUR, Les héritiers contrariés. Essai sur le spirituel républicain au XIX ${ }^{\mathrm{e}}$ siècle
}

\author{
Christophe Voilliot
}

\section{RÉFÉRENCE}

Julien PASTEUR, Les héritiers contrariés. Essai sur le spirituel républicain au XIXe siècle, Paris, Les Belles Lettres, « essais », 2018, 503 p., 25,90€.

1 Issu d'une thèse de philosophie soutenue en 2015 à l'université Paris-Nanterre, ce livre mérite néanmoins l'appellation d'essai qui figure dans le sous-titre. En effet, dans une perspective qui est celle de Charles Péguy, Julien Pasteur envisage le $\mathrm{xIX}^{\mathrm{e}}$ siècle comme une totalité ensevelie par une "grande pulsion matérialiste » (p. 323) où la Révolution française figure la «scène primitive ». Péguy «flétrit très injustement l'avilissement général causé par le XIX siècle au nom d'une catastrophe qui n'arrive vraiment qu'au $\mathrm{XX}^{\mathrm{e} 1}$ ", nous rappelle Bruno Latour et c'est pourquoi il peut servir de miroir à tous ceux qui considèrent que les Modernes nous entraînent dans un abyme. Mais Péguy est aussi un « habile lecteur » qui « voit trop juste» (p. 471) et après lequel l'auteur peut mettre en œuvre à son tour un ambitieux programme de lecture (Joseph de Maistre, Auguste Comte, Tocqueville, Marx, Proudhon). Si Michelet occupe une place aussi importante et centrale d'un point de vue chronologique - dans sa démonstration, c'est d'ailleurs parce que Péguy l'a alerté sur le sort fait à l'historien: "C'est pour cela que l'on est exposé à être extrêmement injuste envers Michelet et tous ceux de sa race ${ }^{2}$ ». Quel est le ressort de cette injustice ? Écraser le "spirituel républicain " pourtant omniprésent dans la langue du XIX ${ }^{e}$ siècle et de ses penseurs. La thèse de Julien Pasteur vise donc à mettre fin à une "alternative délétère» (p.451) dont nous aurions hérité des Modernes, soit considérer comme récessifs et donc sans grand intérêt les sentiments religieux qui survivent dans les sociétés contemporaines, soit considérer au contraire, à 
l'instar de Guizot, que toute politique peut se résumer à un gouvernement des esprits. C'est pourquoi «la philosophie républicaine du XIXe siècle français ne cesse de nous ramener à ce point qui [aux yeux de l'auteur] est centrifuge : il n'y a pas de société sans pouvoir spirituel » (p. 451). Dès lors, se trouve résolue «l'énigme d'un sacré moderne » (p.65), transféré dans le républicanisme sous la forme d'une "expérience de pensée » (p. 154) qui, dans le cas français, peut se résumer en une métaphysique de l'exception révolutionnaire. Il est impossible ici d'entamer une discussion pour chacun des auteurs étudiés. Concernant Michelet en tout cas, le doute n'est pas possible si l'on suit ce qu'il écrivait dans son journal le 21 janvier 1849 : «Plus tard, je pénètre au monde profond, mystérieux de l'âme individuelle et, dans une âme retrouvant les barrières et divisions qui divisaient les cités, apercevant dans un même homme des factions, des guerres civiles, des tyrannies, j'entreprends de réconcilier cet homme avec lui-même ; je le prie de fonder en lui une sage et forte république ${ }^{3} »$.

Il serait possible d'expliquer autrement ce "remaniement inédit de la subjectivité » (p. 458 note 16) qui traverse le siècle, en particulier en prenant appui sur la sociologie durkheimienne. Mais en réduisant cette dernière, dans le prolongement de Bruno Karsenti ${ }^{4}$, à une physique sociale qui ne serait que « le spirituel républicain parvenu à l'âge de raison" (p.368) sans prendre au sérieux la rupture épistémologique qui la sous-tend, Julien Pasteur demeure prisonnier du dilemme qu'il énonce pourtant: " Faute d'une authentique pensée sociale, capable de rendre compte rationnellement de l'inscription du collectif dans l'individuel, l'héritage de 1789 nous condamne à tourner dans un cercle vicieux» (p.452). En s'intéressant aux processus par lesquels «le jugement individuel s'est émancipé du jugement collectif $»^{5}$, Durkheim proposait pourtant une perspective qui ne se limitait pas au constat de l'émergence de l'individualisme dans les sociétés modernes. C'est pourquoi on peut également regretter que l'auteur, tout en hypostasiant la rupture révolutionnaire et ses conséquences sur le langage ne discute pas la thèse de l'émergence, à cette époque, d'un nouveau régime d'historicité. La réponse de François Hartog à l'interpellation de Péguy sur le traitement du présent est tout autre en effet $^{6}$. Elle nous conduit à faire de la spiritualité un objet d'histoire soumis à l'expérience du temps tout en faisant l'économie d'un récit théologico-politique qui ferait de la République un «corps spirituel». On regrettera enfin dans ce livre l'abus de formules générales qui ne résisteraient pas à l'explicitation historienne, ou qui font du XIX siècle le sujet de l'action, voire aussi l'effacement d'auteurs (Victor Hugo...) dont la contribution au républicanisme ne peut si facilement être passée sous silence ${ }^{7}$.

\section{NOTES}

1. Bruno Latour, " Nous sommes des vaincus », in Camille Riquier (dir), Charles Péguy, Éditions du Cerf, « Les cahiers du Cerf », 2014, p. 15.

2. Charles Péguy, L'Argent, suivi de L'Argent (suite) [1913], Paris, Gallimard, 1932, p. 11. Cité p. 470.

3. Jules Michelet, Journal. Choix et édition de Perrine Simon-Nahum, Paris, Gallimard, "folioclassique ", 2017, p. 599. 
4. Bruno Karsenti, D'une philosophie à l'autre : les sciences sociales et la politique des modernes, Paris, Gallimard, 2013.

5. Émile Durkheim, De la division du travail social, Paris, Félix Alcan, 1893, p. 459.

6. François Hartog, Régimes d'historicité. Présentisme et expériences du temps, Paris, Le Seuil, « La librairie du XXI ${ }^{\mathrm{e}}$ siècle ", 2003.

7. Jean-Claude Caron, Annie Stora-Lamarre (dir), Hugo politique. Actes du colloque de Besançon (11-13 décembre 2002), Besançon, Presses universitaires de Franche-Comté, « historiques », 2004. 